\title{
Analytical Velocity Study in a Conical Diffuser with Screw Tape Inserts
}

\author{
Ehan Sabah Shukri \\ Department of electronic technology, Engineering Technical College-Baghdad, Middle Technical University (MTU) Baghdad, Iraq
}

\begin{abstract}
A study is made to enhance the rate of velocity distribution in a conical diffuser. In this work, a numerical analysis on screw tape inserts in a conical diffuser is presented. In the numerical simulations, the swirling flow was introduced by using rectangular screw tape placed inside the inner test wall of the conical diffuser. Screw tape with different aspect ratios (AS) 2.5, 3.5, 4.5, 6.5 and 7.5 was analysed. The simulations were carried out with constant inlet condition considering the flow turbulent and incompressible with inlet Reynolds number $3.2 \times 10^{5}$. The simulations were performed using air as a working fluid. The results obtained from the conical diffuser with screw tape inserts are compared with those without screw tape (plain conical diffuser). On the basis of the same inlet boundary conditions for the screw tape in the conical diffuser and the plain conical diffuser, it was found that the velocity distribution performance of screw tape inserts with different AS is better than plain conical diffuser. It is also observed that the screw tape with AS 3.5 offered the best velocity distribution rate.
\end{abstract}

\section{Introduction}

Turbulent flows in passages with gradually varying crosssectional area are present in several applications in different engineering branches, especially where the geometric limitations are required like turbo-machinery. It has long been the subject of interest from the scientific community. Diffusers are devices of divergent area play an important role in many fluid machines to convert kinetic energy into pressure energy. Flow through diffuser has numerous industrial applications, and needs to be understood in more details. Therefore considerable amount of experimental and numerical investigations has been carried out on conical diffusers [1-4].

A swirl flow is a fluid flow contains a noticeable tangential velocity component and it can provide notable fluid mixing. In recent year, these kinds of flows have received more attention. They are attractive for many heat transfer and mixing applications. Therefore, many studies have focused on the swirl flows. It is widely used in industrial combustion devices such as gas turbine combustors, furnaces, burners to provide power generation. It has a dominant effect on the mixing process in gas turbine combustion chamber [5-8].

Eldrainy et al. [9-10] examined the effect of different swirler geometries on the flow dynamics inside a micro gas turbine combustion chamber model. Designing air swirler to produce stable and efficient combustion with low-pressure losses was a challenge. Axial flat vane swirler with different vane angles was tested. The simulated results confirmed that weak swirl with low swirl number was not sufficient to produce a strong centrifugal force. Consequently, if the swirler vane angle increased, both swirl number and flow deflection angles were increased. Moreover, extra pressure reduction was occurred, and the reversed flow was increased as well, so as a conclusion, with high deflection angles, turbulence intensity increased and the mixing process will be promoted [9]. Furthermore, Eldrainy et al. [10] confirmed that swirl number under 0.4 , recirculation would not be observed. Therefore, mixing applications should be designed for swirl number more than 0.6. Thus, controlling such parameters, the mixing process can be improved. Swirling flow is one of the passive techniques that usually accompanied with high tangential velocity and turbulence intensity, which provides an additional mechanism to increase the mixing.

Most attention has been given to strong recirculating swirling flow in diffusers, for their extensively used in fluid mechanical devices. To increase mixing and combustion intensity, a study had been conducted numerically and experimentally [11]. It was carried out with flat and curved vanes. Four different vane angles $\left(40^{\circ} 50^{\circ}\right.$ and $\left.60^{\circ}\right)$ in the inlet of a combustion chamber were examined. Comparing the results between numerical and experimental method, it was found that the higher the vane angle, the greater the swirling flow, and the larger the recirculation zone. The results showed that the flat vane was more effective than the curved vane for numerical and experimental methods.

Numerical simulations have been successfully used by many authors to describe swirling flows. Therefore, the aim of the present numerical study is mainly on velocity distribution analysis in a conical diffuser with screw tape inserts. The effect of different aspect ratios of the screw-tape on velocity distribution are simulated and 
analyzed by means of CFD software. All of the simulations are achieved at the same inlet conditions with Reynolds number $\left(\operatorname{Re}=3.2 \times 10^{5}\right)$. Results for the velocity distributions along the conical diffuser are compared with those of the plain conical diffuser.

\section{Geometrical models}

Numerical calculations were carried out for the conical diffuser fitted with screw tape inserts. Model geometries presented in Figure 1 and Table 1.

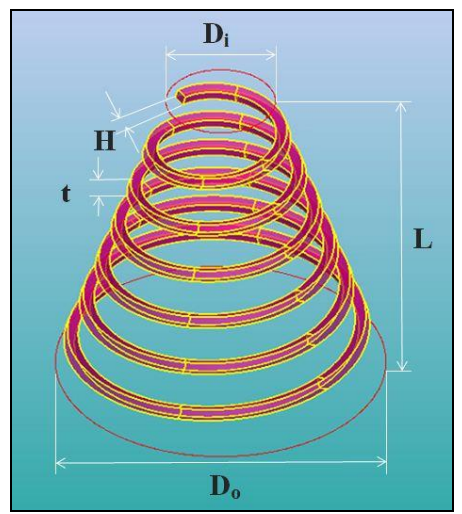

Figure 1. Diffuser and Screw tape geometries.

Table 1. Simulated model geometries.

\begin{tabular}{|c|c|}
\hline Model geometries & Values, $\mathbf{~ m}$ \\
\hline Inlet diameter $\left(\mathrm{D}_{\mathrm{i}}\right)$ & 0.048 \\
\hline Outlet diameter $\left(\mathrm{D}_{\mathrm{o}}\right)$ & 0.145 \\
\hline Diffuser length $(\mathrm{L})$ & 0.14 \\
\hline Screw tape width $(\mathrm{t})$ & 0.002 \\
\hline Screw tape height $(\mathrm{H})$ & $0.005,0.007,0.009,0.011$ and \\
& 0.013 \\
\hline
\end{tabular}

\subsection{Boundary layer}

The simulations were analysed with air as the working fluid. Assumptions were made to model the velocity profile in a conical diffuser fitted with a screw tape. The main assumptions are:

1. The flow in the conical diffuser fitted with screw tape is turbulent and incompressible.

2. The flow is steady.

3. Inlet Reynolds number is $\left(\mathrm{Re}=3.2 \times 10^{5}\right)$ based on the hydraulic diameter of the conical diffuser $\left(D_{h}\right)$ which is the inlet diameter of the diffuser $\left(\mathrm{D}_{\mathrm{i}}\right)$.

4. The physical properties of the fluid at the conical diffuser inlet are constant.

It is set that the physical properties of the working fluid (air) have been considered as the density (1.225 $\mathrm{kg} / \mathrm{m}^{3}$ ) and the dynamic viscosity $(1.7894 \mathrm{e}-05 \mathrm{~kg} / \mathrm{m} . \mathrm{s})$. The static pressure at the outlet is set as zero.

\section{Numerical models}

In the present study, numerical investigation was carried out with a screw tape inserts in a conical diffuser. The commercial software ANSYS FLUENT 16.1 was chosen as the CFD tool for this work. The standard $k-\varepsilon$ model was applied as a turbulence model. The turbulence kinetic energy $k$ and its rate of dissipation $\varepsilon$ calculations followed literature reference. Standard $k-\varepsilon$ turbulence model was allowed to predict the heat transfer and fluid flow characteristics. This turbulence model has been successfully applied to flows with engineering applications including internal flows [12]. The turbulence kinetic energy $k$ and its rate of dissipation $\varepsilon$ was obtained from the following transport equations [13],

$$
\begin{gathered}
K=3 / 2(V I)^{2} \\
I=0.16(\text { Re })^{-1 / 8} \\
\varepsilon=\left(C \mu^{3 / 4} \cdot K^{3 / 2}\right) l^{-1} \\
l=0.07 L
\end{gathered}
$$

where, $V$ is the inlet velocity magnitude, $I$ is the initial turbulence intensity, Re Reynolds number, $C \mu$ is a $k-\varepsilon$ model parameter whose value is typically given as $0.09, l$ is the turbulence length scale and $L$ is a characteristic length. For this study, $L$ is considered as the hydraulic diameter.

In this numerical study, the finite volume method has been used to discretize the partial differential equations of the model. The unstructured tetrahedral meshes are generated as shown in Figure 2.

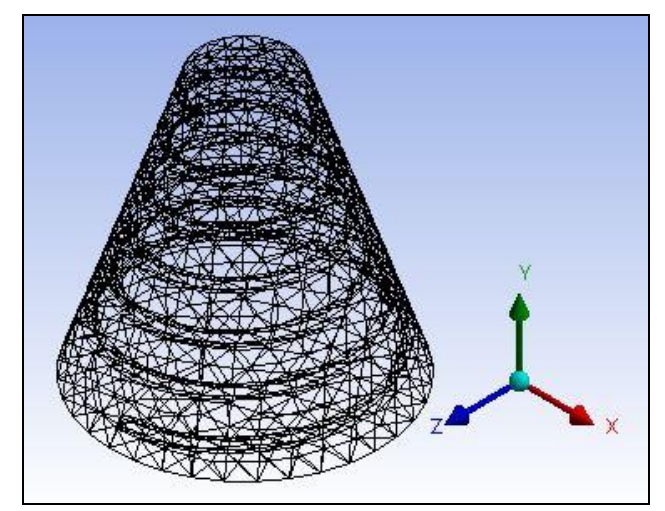

Figure 2. Model mesh generation.

\section{Results and discussion}

Velocity distribution is numerically investigated for a conical diffuser fitted with screw tape inserts to study flow velocity profile.

\subsection{Effect of the screw tape inserts with different aspect ratios (AS)}

In the present study, numerical results are analysed and discussed for different aspect ratios AS $(2.5,3.5,4.5,5.5$, 6.5 and 7.5) in a conical diffuser fitted with screw tape inserts. They are represented by the Figures 3-8. These Figures visualized the performance of the screw tape on the axial velocity distribution. Figure 9 shows the velocity distribution in a conical diffuser without screw tape (plain conical diffuser). 


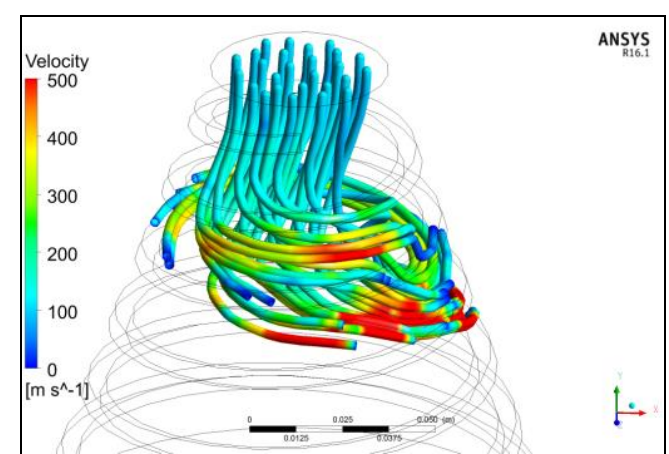

Figure 3. Velocity distribution with aspect ratio 2.5.

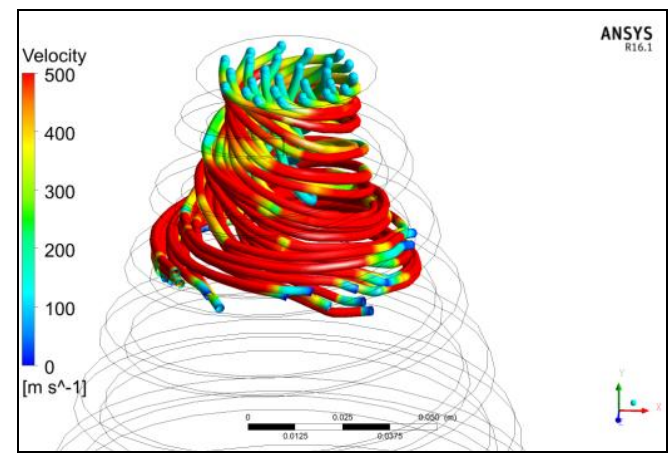

Figure 4. Velocity distribution with aspect ratio 3.5.

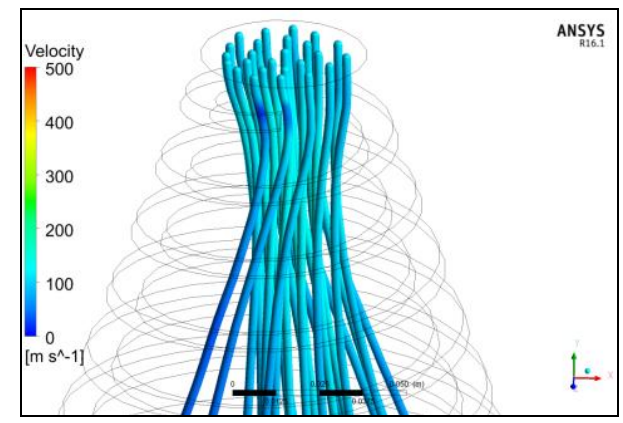

Figure 5. Velocity distribution with aspect ratio 4.5.

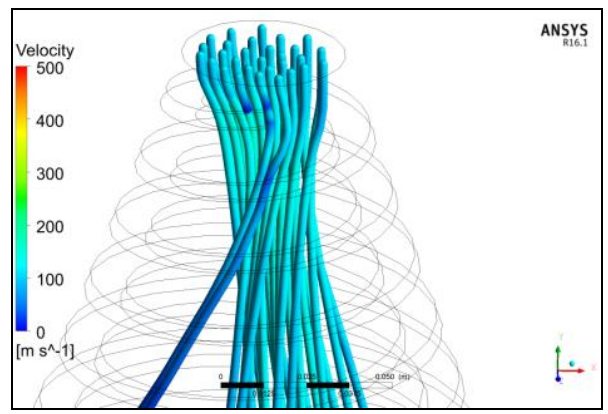

Figure 6. Velocity distribution with aspect ratio 5.5.

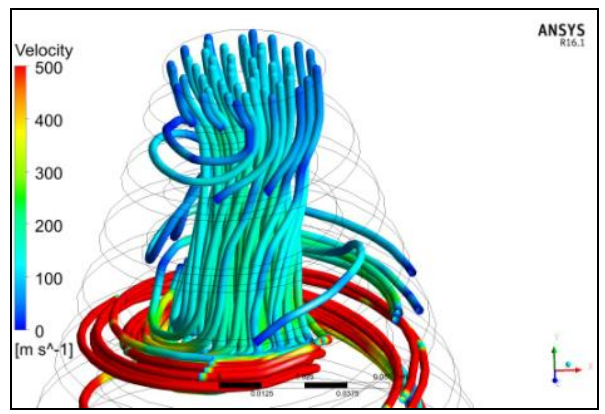

Figure 7. Velocity distribution with aspect ratio 6.5.

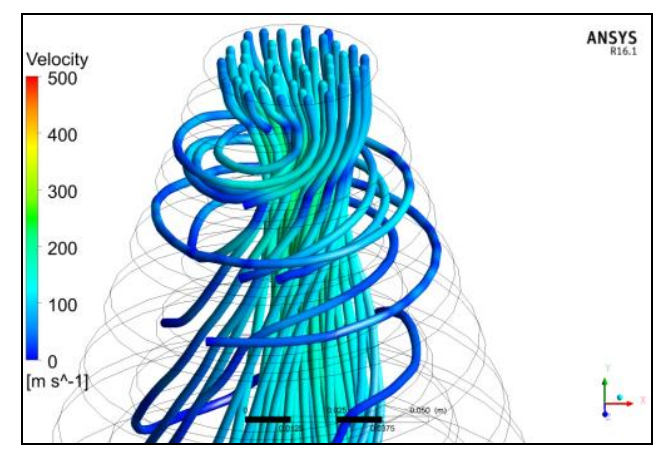

Figure 8. Velocity distribution with aspect ratio 7.5.

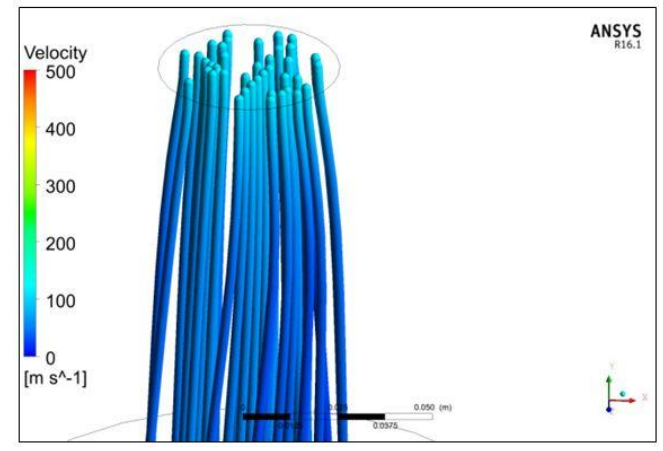

Figure 9. Velocity distribution in a plain conical diffuser.

Figure 3 shows velocity distribution for aspect ratio 2.5. It is found that with the existence of the screw tape, the flow velocity is started to distribute in a helical motion and this due to the increase of the turbulence that will be induced by the screw tape inserts.

Velocity distribution for aspect ratio 3.5 is illustrated in Figure 4. It can be seen that the phenomenon appears to be similar to the previous Figure but with a better effect.

Figures 5-6 present the effect of aspect ratios (4.5 and 5.5). On comparing these aspect ratios, it has been observed that velocity distribution performance is less than the previous aspect ratios (2.5 and 3.5).

Moreover, the velocity distribution for aspect ratios (6.5 and 7.5) is shown in Figures 7-8. In these Figures, it is clear that the velocity will distribute in the radial direction and the flow direction. For comparison purposes, the velocity distribution was simulated in a plain conical diffuser as shown in Figure 9.

It is found that the velocity distribution rate with the aspect ratio 3.5 is higher than those from other ratios (2.5, $4.5,5.5,6.5$ and 7.5) and this means that the turbulent intensity obtained from the screw tape aspect ratio 3.5 is higher than the other tested aspect ratios.

Furthermore, the simulated results of the velocity distribution of screw tapes inserts for the tested aspect ratios are compared with simulated data for a plain conical diffuser. It is found that the screw tape inserts offered an additional velocity distribution enhancement with more helical motions and recirculation.

The variation of the velocity distribution with the flow direction for different screw tape aspect ratios AS $(2.5,3.5,4.5,5.5,6.5$ and 7.5$)$ in a conical diffuser and a plain conical diffuser is displayed in Figure 10. The velocity distribution for these inserts was enhanced compared to the plain conical diffuser. Highest velocity 
distribution was obtained for screw tape with aspect ratio 3.5. This result is mainly due to the effects of the helical motion of the flow and turbulence generated by the screw tape inserts which leads to create better flow mixing between the fluids at the core and the diffuser inner wall.

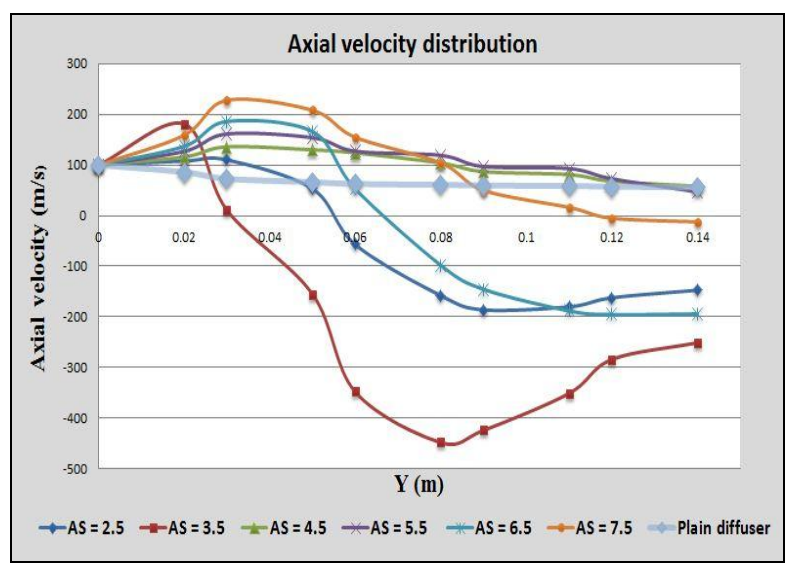

Figure 10. Simulated velocity distribution of the screw tape inserts for different aspect ratios AS.

\section{Conclusions}

In the present numerical study, velocity distribution in a conical diffuser was investigated. The flow was disturbed by screw tape inserts in a conical diffuser with air as working fluid. The performance of the screw tape inserts was evaluated for different aspect ratios AS (2.5, 3.5, 4.5, 5.5, 6.5 and 7.5). For comparison, numerical study with the same inlet boundary conditions for the plain conical diffuser was carried out. Based on the numerical simulation results, conclusions can be made as follows,

1. The augmentation of the velocity distribution with screw tape inserts has shown a significant improvement as compared to conical diffuser without screw tape (plain conical diffuser).

2. The values of the velocity distribution rate for the conical diffuser with screw tape aspect ratio AS 3.5 are noticeably higher than the other values of the tested aspect ratios for the conical diffuser fitted with screw tape and the plain conical diffuser as well. The best performance for the velocity distribution rate was offered by this aspect ratio.

\section{References}

1. M. Benisek, D. Ilic, D. Cantrak and I. Bozic "Investigation of the turbulent swirl flows in a conical diffuser" Thermal Science, 14, no. suppl., pp. 141-154, (2010).

2. R. Prakash, D. Christopher and K. Kumarrathinam "CFD analysis of flow through a conical exhaust" International Journal of Research in Engineering and Technology, 3, pp. 239-248, 11 (2014).
3. N.V. Mahalakshmi, G. Krithiga, S. Sandhya, J. Vikraman, V. Ganesan, Experimental investigations of flow through conical diffusers with and without wake type velocity distortions at inlet, Experimental Thermal and Fluid Science, 32, pp.133-157, (2007).

4. K. P. Skotniczny, "Numerical analysis of the impact of conical diffuser geometry change on velocity distribution in its outlet cross-section" Mechanics, 25, 2 (2006).

5. T. Tanneberger, T. G. Reichel, O. Krüger, S. Terhaar, C. Paschereit, Numerical investigation of the flow field and mixing a swirl stabilized burner with a nonswirling axial jet, Proceedings of ASME Turbo Expo 2015: Turbine Technical Conference and Exposition GT2015, pp. 1-12, 2015.

6. R. Orl, Experimental study of passive scalar mixing in swirling jet flows, Technical reports from Royal Institute of Technology KTH Mechanics SE-100 44 Stockholm, Sweden, (2006).

7. K. G. Kulkarni, S. Y. Bhosale, Experimental Investigation of Heat Transfer Enhancement by Using Clockwise and Counter -clockwise Corrugated Twisted Tape Inserts, International journal of innovations in engineering research and technology ISSN: 2394-3696, 2, ISSUE 5, ( 2015).

8. T. Parra, R. Perez, M. Rodriguez, F. Castro, R. Szasz, A. Gutkowski, Numerical Simulation of Swirling Flows -Heat Transfer Enhancement, Journal of Fluid Flow, Heat and Mass Transfer, 2, ISSN: 2368$6111, .(2015)$.

9. Y. A. Eldrainy, J. Jeffrie and M. Ridzwan "Prediction of the flow inside a micro gas turbine combustor" Jurnal Mecchanikal, no. 25, pp. 50-63, 2008.

10. Y. A Eldrainy, H. S. Aly, K. M. Saqr and M. N. Jaafar "A multiple inlet swirler for gas turbine combustors " Proceeding of The International Conference on Fluid Mechanics, Heat Transfer and Thermodynamics, World Academy of Science, Engineering and Technology Tokyo, Japan, 3, pp. 1260-1263, 5 (2009).

11. M. Jaafar Nazri and K. Jusoff "Combustor aerodynamic using radial swirler " International Journal of Physical Sciences, 6, no. 13, pp. 30913098, (2011).

12. D. Erdemir, S. Gunes, V. Ozceyhan, and N. Altuntop, Numerical investigation of heat transfer enhancement and pressure drop in heat exchanger tube fitted with dual twisted tape elements, World Scientific and Engineering Academy and Society (WSEAS, ISSN: 2227-4596), pp.167-172, (2013).

13. D. Flórez-Orrego, W. Arias, D. López, and H. Velásquez, Experimental and CFD study of a single phase cone-shaped helical coiled heat exchanger: an empirical correlation, Proceedings of the 25th International Conference on Efficiency, Cost, Optimization, Simulation and Environmental Impact of Energy Systems, pp. 375-394, (2012). 